\title{
Contribution of coagulant and native microflora to the volatile-free fatty acid profile of an artisanal cheese
}

\author{
Freni K. Tavaria, Tânia G. Tavares, A.C. Silva-Ferreira, F. Xavier Malcata* \\ Escola Superior de Biotecnologia, Universidade Católica Portuguesa, Rua Dr. António Bernardino de Almeida, P-4200-072 Porto, Portugal
}

Keywords: SPME; LAB; Cynara cardunculus; Serra da Estrela cheese; VFA

\begin{abstract}
The contributions of the coagulant Cynara cardunculus and of the microflora of raw milk to the volatile-free fatty acid profile of Serra da Estrela cheese were evaluated. The experimental design included both a model system and, dual cheeses. The study in the model system showed that isovaleric acid was the predominant volatile compound after $7 \mathrm{~d}$ of ripening. The systems inoculated with Enterococcus faecium produced the highest amount of this volatile (ca. $135.8 \mathrm{mg} \mathrm{kg}^{-1}$ curd), while those inoculated with Lactobacillus plantarum produced the least $\left(21.4 \mathrm{mg} \mathrm{kg}^{-1}\right.$ curd); Lactococcus lactis produced moderate amounts (ca. $34.2 \mathrm{mg} \mathrm{kg}^{-1}$ curd) but a total amount of volatile-free fatty acids similar to those found in control samples. This is considered advantageous since this volatile fatty acid confers a harsh, piquant, mature flavour to cheese, coupled with the realisation that excess volatiles may result in off-flavours. The addition of cultures in experimental cheeses helped reduce ripening time to about one half. Inclusion of Lb. plantarum led to cheeses containing the highest amounts of volatiles, and exhibiting an aroma closest to that of typical Serra da Estrela cheese.
\end{abstract}

\section{Introduction}

Conditions prevailing in cheese (moisture, $\mathrm{pH}$ and salt content), as well as environmental conditions (temperature, humidity and ripening time) determine the quality and extent of degradation of proteins, carbohydrates and fat effected by starter and non-starter microorganisms and their enzymes, as well as by indigenous milk enzymes and coagulant enzymes (Fox \& Wallace, 1997). Several studies have evaluated the aroma profile of a variety of cheeses (Bosset \& Gauch, 1993; Frutos, Sanz, \& Martínez-Castro, 1991; Lawlor, Delahunty, Wilkinson \& Sheehan, 2002; Vandeweghe \& Reineccius, 1990) and it has become clear that cheese flavour is not linked to a small number of impact compounds, but is rather the result of a delicate balance between a complex blend of components (Dirinck

\footnotetext{
*Corresponding author. Tel.: + 351225580004 ; fax: + 351225090351.

E-mail address: fxmalcata@esb.ucp.pt (F.X. Malcata).
}

\& de Winne, 1999), resulting from the aforementioned metabolic pathways.

It is well documented (Buchin et al., 1998; Grappin \& Beuvier, 1997) that cheeses manufactured from pasteurized milk with added commercial starters do not exhibit very intense flavours, nor as varied as cheeses manufactured with raw milk (Ayad, Verheul, Wouters, \& Smit, 2000). According to Buchin et al. (1998), the indigenous milk microflora seems to be responsible for the production of the intense flavour in raw milk cheeses which is associated with higher amounts of fatty acids, alcohols and sulphur compounds. Restrictions imposed by the World Health Organization, coupled with consumers' demand for microbiologically safer products, yet bearing the typical properties of their traditional counterparts, have thus provided an impetus to search for new processing technologies. One such example is the inclusion of strains of microorganisms previously isolated from traditional products. Autochthonous cultures have been successfully used to improve the sensory quality of several Spanish cheeses, such as 
Cebreiro, Arzúa-Ulloa and Tetilla (Centeno, Menéndez, Hermida, \& Rodríguez-Otero, 1999; Menéndez, Centeno, Godínez, \& Rodríguez-Otero, 2000; Menéndez, Godínez, Hermida, Centeno, \& Rodríguez-Otero, 2004).

The profile of volatile compounds of Serra da Estrela cheese has been studied (Tavaria, Silva-Ferreira, \& Malcata, 2004) throughout the typical maturation period, and volatile fatty acids were found to be major contributors to the overall aroma of that cheese. In order to assess the individual contributions of the ripening agents, cheeselike model systems were chosen that can easily be held under aseptic conditions, and in which long-term effects can be studied in shorter timeframes. Raw ewes milk, curdled with Cynara cardunculus (as used in Serra da Estrela cheese manufacture), and inoculated with four randomly selected isolates (belonging to the genera Lactobacillus, Leuconostoc, Lactococcus and Enterococcus) - one at a time or all combined, was used as a model system in this study. Cheeses were also manufactured using two of the above isolates as starters.

The objective of the present study was thus to evaluate whether or not whole-cells of the selected isolates were able to produce aroma compounds from milk in model systems and in cheese, and to compare the performance of those selected isolates in the two systems.

\section{Materials and methods}

\section{Microorganism selection}

Several isolates from ripened Serra da Estrela cheese were identified according to their electrophoretic protein profile, using sodium dodecyl sulphate polyacrylamide gel electrophoresis (SDS-PAGE) (Kersters, 1985). From these, four isolates identified as Lactobacillus plantarum ESB323, Leuconostoc mesenteroides ESB327, Lactococcus lactis ESB331 and Enterococcus faecium ESB338 have been kept as pure cultures in our culture collection, and were selected for this study.

\section{Cheese-like model system}

The model system consisted of raw ewes milk (from the Bordaleira Serra da Estrela breed) with added microorganisms, and/or curdled with a plant coagulant - an aqueous extract of $C$. cardunculus, as described below. Sodium azide at $0.1 \%(\mathrm{w} / \mathrm{v})$ was added (or not) to coagulated samples to prevent microbial growth. Some milk samples were coagulated with $100 \mu \mathrm{L}$ liquid animal rennet (NaturenStab 230, Chr. Hansen, Graasten, Denmark) $100 \mathrm{~mL}^{-1}$ milk, for comparison. The microorganisms used to inoculate the milk were: Lb. plantarum (LB), Leuc. mesenteroides (LEU), Lc. lactis (LC) or E. faecium (ET) (at $1 \mathrm{~mL} 100 \mathrm{~mL}^{-1}$ milk), or all four isolates together (MX) (each at $0.25 \mathrm{~mL} 100 \mathrm{~mL}^{-1}$ milk). Bacterial density was determined by standard plate counts $\left(\mathrm{cfumL} \mathrm{m}^{-1}\right)$. The aforementioned amounts of inocula were comparable to the concentration of microorganisms typically encountered in this variety of cheese (ca. $1.0 \times 10^{8} \mathrm{cfu} \mathrm{g}^{-1}$ cheese). The coagulant was prepared as follows: $2.5 \mathrm{~g}$ of thistle flowers was macerated with $25 \mathrm{~mL}$ of citrate buffer $(0.1 \mathrm{M}, \mathrm{pH} 3.0)$. The homogenate was centrifuged for $10 \mathrm{~min}$ at $2540 \mathrm{~g}$ in a Universal 32R Hettich Centrifuge (Tuttlingen, Germany), and then filtered through Whatman No. 1 filter paper. From this extract, $400 \mu \mathrm{L}$ was then added to $100 \mathrm{~mL}$ of raw milk in a sterile $250 \mathrm{~mL}-\mathrm{Sch}$ tt bottle, to achieve a final concentration of $0.4 \mathrm{~g} \mathrm{~L}^{-1}$ (which is the concentration typically used in Serra da Estrela cheese manufacture). The bottles were capped, and coagulation was allowed to occur at $30^{\circ} \mathrm{C}$ for $45 \mathrm{~min}$. The coagulum was cut at random with a sterile knife, and the whey was drained without pressing. Samples were incubated at $8-10^{\circ} \mathrm{C}$ and a relative humidity of $95 \%$ until sampling, which took place at 0,7 , 14,28 and $45 \mathrm{~d}$. Untreated raw milk was used as a second control.

The $\mathrm{pH}$ of the curdled milk samples was directly measured using a MicropH $2001 \mathrm{pH}$ meter (Crison, Alella, Spain). Analytical duplicates were measured for all samples.

\section{Experimental cheeses}

Fourteen $1 \mathrm{~kg}$-cheeses were manufactured in four batches: batch LC-raw milk with $1 \%(\mathrm{v} / \mathrm{v})$ Lc. lactis; batch LB-raw milk with $1 \%(\mathrm{v} / \mathrm{v})$ Lb. plantarum; batch MX-raw milk with $0.5 \%(\mathrm{v} / \mathrm{v})$ Lb. plantarum and $0.5 \%$ (v/v) Lc. lactis; and batch CT-raw milk without addition of starter culture (control). Cultures were added in amounts that attained a final concentration of $1.0 \times 10^{8} \mathrm{cfu} \mathrm{g}^{-1}$ cheese. For each batch, $90 \mathrm{~L}$ of raw milk was filtered through a fine, clean cloth, and poured into a doublewalled, food grade steel coagulation vat with controlled temperature. After the temperature of the milk had reached $30{ }^{\circ} \mathrm{C}$, starter cultures (or plain sterile $10 \%$ skim milk, used as a control) were added, and gently mixed with a stirrer. Milk was sterilized in an autoclave at $110^{\circ} \mathrm{C}$ for $10 \mathrm{~min}$, and the process was validated by checking the viable counts in plate count agar (Merck, Darmstadt, Germany). Crude kitchen salt $\left(20 \mathrm{~g} \mathrm{~L}^{-1}\right.$ milk) and dry thistle flower (C. cardunculus L., $0.4 \mathrm{~g} \mathrm{~L}^{-1}$ milk) were placed inside a cloth, submerged in the milk and agitated until complete solubilization of the salt. The milk was then allowed to coagulate at $32{ }^{\circ} \mathrm{C}$ for $45 \mathrm{~min}$, after which time the coagulum was cut by stirring it with $20 \times 20 \mathrm{~mm}^{2}$ knives. Ten minutes later, the curd pieces were poured into a fine cloth bag, which was closed and firmly pressed to expel the whey. Each cheese was surface-labelled using a food-grade casein marker (Gist Brocades, Delft, The Netherlands). Drainage of whey was completed by using a standard pneumatic press (Albinox Construções, S. Pedro do Sul, Portugal). The cheeses were then placed in the maturation room, at a temperature of $8-9{ }^{\circ} \mathrm{C}$ and a relative humidity of $95 \%$. The cheeses were sampled at $0,7,14,28,45$ and $63 \mathrm{~d}$ after manufacture. 


\section{Microbiological analyses}

At selected time intervals $(0,7,14,28,45$ and $63 \mathrm{~d})$, all samples were assayed for microbiological load: the cheeses were sampled up to $63 \mathrm{~d}$, whereas the model systems were only sampled up to $45 \mathrm{~d}$. For this purpose, $1 \mathrm{~g}$ of curdled milk or $10 \mathrm{~g}$ of cheese (as appropriate) was mixed thoroughly in 9 or $90 \mathrm{~mL}$, respectively, of $2 \%$ (w/v) sodium citrate and homogenized using a Stomacher Lab-Blender 400 (Seward Medical, London, UK). Serial decimal dilutions were made in $0.1 \%(\mathrm{w} / \mathrm{v})$ peptone, and spreadplated on De Man, Rogosa and Sharpe (MRS) agar (Merck, Darmstadt, Germany) for Lb. plantarum and Leuc. mesenteroides, or on M17 (Merck, Darmstadt, Germany) agar for Lc. lactis and E. faecium. Plates were incubated anaerobically at $30^{\circ} \mathrm{C}$ for $3-5 \mathrm{~d}$, and colonies were counted after that period.

\section{Volatile free fatty acid analyses}

Volatile fatty acids (VFAs), in curdled milk samples and in experimental cheeses, were analysed by gas chromatography-mass spectrometry (GC-MS), using solid phase micro-extraction (SPME); a $10 \mathrm{~g}$-sample was homogenized with a stirring bar in a glass flask, maintained in a water bath at $45^{\circ} \mathrm{C}$ and allowed to equilibrate for $5 \mathrm{~min}$. After homogenization, $100 \mu \mathrm{L}$ of (internal standard) octan-3-ol (IS), in a hydro-alcoholic solution $(1: 1, \quad \mathrm{v} / \mathrm{v})$ at $461.97 \mathrm{mg} \mathrm{L}^{-1}$, was added. The SPME fiber assembly (from Supelco, Bellefonte PA, USA), using a divinylbenzene/carboxen/polydimethylsiloxane (DVB/CAR/PDMS) fiber coating, was then introduced, and left to trap the volatiles for $1 \mathrm{~h}$.

Resolution was carried out in a GC apparatus (Finnigan Mat, San Jose CA, USA), equipped with a $50 \mathrm{~m} \times$ $0.25 \mathrm{~mm} \times 0.39 \mathrm{~mm}$ nitroterephthalic acid modified polyethylene glycol capillary column (FFAP CP-Wax 58) (Varian-Chrompack, Walnut Creek CA, USA). Chromatographic conditions were as follows: temperature program $-1 \mathrm{~min}$ at $40^{\circ} \mathrm{C}, 2^{\circ} \mathrm{C} \mathrm{min}^{-1}$ up to $220^{\circ} \mathrm{C}$, and $30 \mathrm{~min}$ at $220^{\circ} \mathrm{C}$; carrier gas- $\mathrm{He}$ (C-60) (Gasin, Matosinhos, Portugal) at $1 \mathrm{~mL} \mathrm{~min}^{-1}$; detection was achieved through an ion trap mass detector (GCQ, Finnigan, San Jose CA, USA), operated in the full scan mode, with $70 \mathrm{mV}$ electron impact, and source and transfer line temperatures of 180 and $190{ }^{\circ} \mathrm{C}$, respectively; the mass range was $29-350 \mathrm{~m} / z$, with a scan rate of $7 \mathrm{scan} \mathrm{s}^{-1}$; the electron multiplier was set according to the autotune procedure; and the identification was based on comparison with mass spectra obtained for a mixture of pure standards injected in the same conditions, with mass spectra of the National Institute of Standards and Technology (NIST) 98 MS library database.

\section{Free amino acid analyses}

Free amino acids (FAAs) in curdled milk samples and in experimental cheeses were determined using the Pico-
$\mathrm{Tag}^{\mathrm{TM}}$ (Waters, Milford MA, USA) method for sample preparation. The FAAs were analysed using two replicates, according to Alonso, Alvarez, and Zapico (1994). The chromatograms were processed using the Millenium 2010 software package (Waters). In order to quantify each FAA, 22 solutions of pure standards (Sigma, St. Louis MO, USA) were prepared $-12.5 \mathrm{~mm}$ for Tyr, and $25 \mathrm{~mm}$ for the other 21 amino acids. Calibration was carried out using hydroxy-proline and nor-leucine as internal standards.

\section{Statistical analyses}

Analysis of variance (ANOVA) (at a significance level of $5 \%$ ) was conducted using the v. 11.5 of the Statistical Package for the Social Sciences (SPSS, Chicago IL, USA). Statistical analysis was carried out using microbial species, type of rennet and ripening time as the main parameters, in the case of the model systems; and microbial species and ripening time as the main parameters, in the case of the experimental cheeses. The experimental errors associated with the measurements were checked to be independent and normally distributed, with constant variance; hence, ANOVA could safely be used on the data in their original form. Additionally, multiple comparisons were carried out using Bonferroni's test (at a level of significance of $5 \%$ ), among the various ripening times for a given microorganism.

\section{Results and discussion}

\section{Cheese-like model system}

The amounts of volatile fatty acids $\left(\mathrm{C}_{2}-\mathrm{C}_{12}\right)$ present in the control samples (i.e. raw ewes milk incubated for $45 \mathrm{~d}$ ) are shown in Fig. 1A, whereas the amounts present in samples of milk coagulated with C. cardunculus or animal rennet are presented in Fig. 1B. Curdled milk samples exhibited lower amounts of VFAs when compared with milk alone - as expected, due to entrapment of volatiles within the curd. On the other hand, milk samples coagulated with plant rennet possessed higher amounts of VFAs than those coagulated with animal rennet, with significant differences $(p<0.05)$ for acetic $\left(\mathrm{C}_{2}\right)$, propionic $\left(\mathrm{C}_{3}\right)$, iso-butyric $\left(\mathrm{iC}_{4}\right)$, butyric $\left(\mathrm{C}_{4}\right)$, decanoic $\left(\mathrm{C}_{10}\right)$ and dodecanoic $\left(\mathrm{C}_{12}\right)$ acids. Differences between the amounts of iso-valeric $\left(\mathrm{iC}_{5}\right)$, hexanoic $\left(\mathrm{C}_{6}\right)$ and octanoic $\left(\mathrm{C}_{8}\right)$ acids were not significant $(p>0.05)$ for both coagulants. The greater proteolytic action promoted by plant rennets (Sousa \& Malcata, 2002) may decrease the proteinaceous fraction in the curd, thus facilitating lipolysis and increasing the levels of VFAs.

A drop in $\mathrm{pH}$ from 6.5 to 4.8 by $45 \mathrm{~d}$ of ripening was observed in samples coagulated with the plant rennet, while those coagulated with animal rennet showed a $\mathrm{pH}$ increase to 6.7 in the same time frame. Similar results have been reported by Reis et al. (2000) for cheeses manufactured with extracts of Centaurea calcitrapa, a related plant 

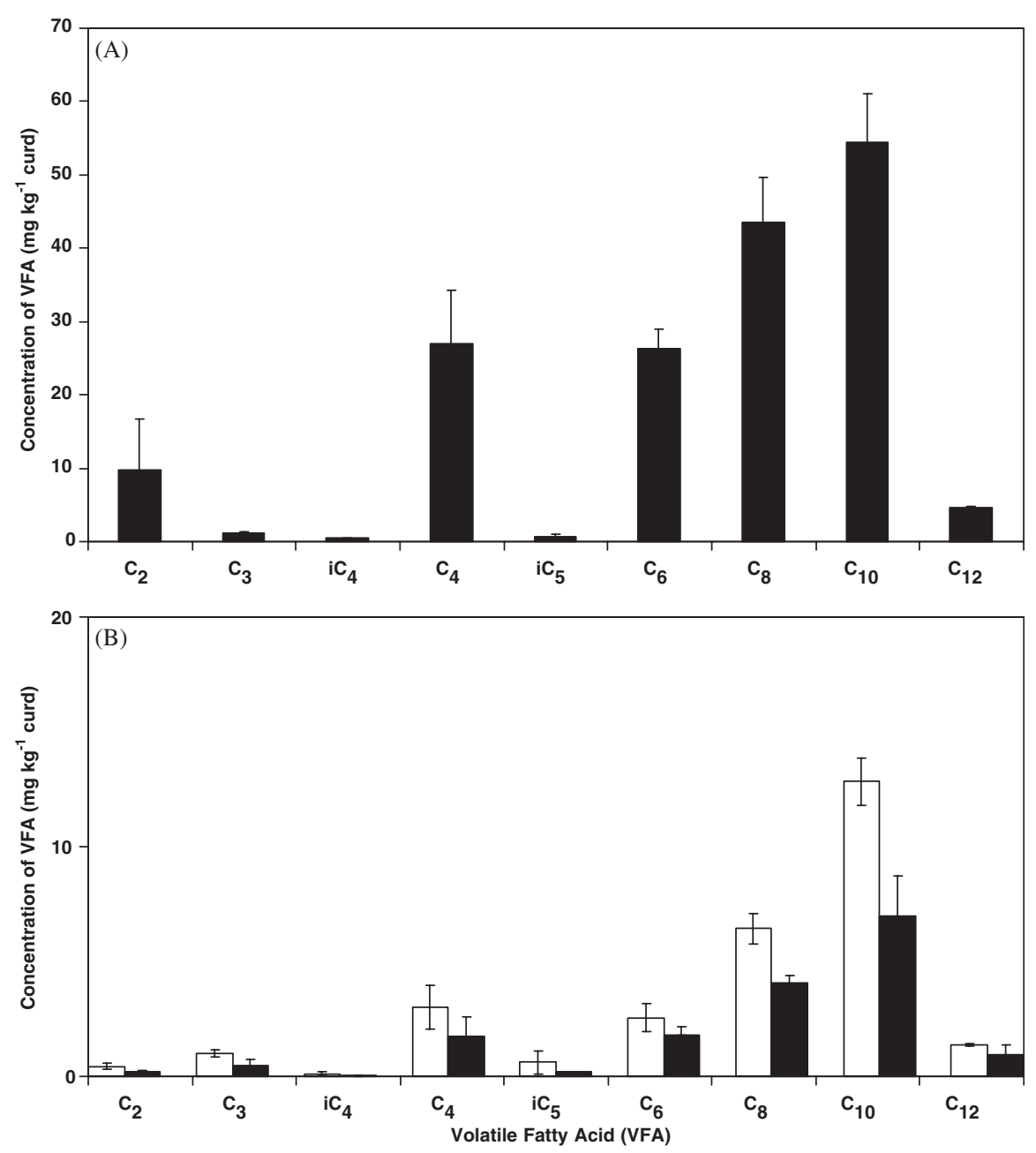

Fig. 1. Concentration (mean \pm standard deviation) of volatile fatty acids (VFAs) $\left(\mathrm{C}_{n}\right.$, where $n$ denotes number of carbon atoms), in milk only (A) and in cheese curd (B), coagulated with Cynara cardunculus (- $\square$-) or animal rennet (-口-), without any starter culture, incubated for $45 \mathrm{~d}$ at $8-10{ }^{\circ} \mathrm{C}$ and $95 \%$ relative humidity $\left(\mathrm{iC}_{4}\right.$, iso-butyric acid; $\mathrm{iC}_{5}$, iso-valeric acid).

rennet. The viable bacterial counts in these samples revealed no significant fluctuations up to $45 \mathrm{~d}$ of incubation, remaining around $\log 8.4-8.9 \mathrm{~g}^{-1}$ curd (data not shown).

Samples inoculated with $L b$. plantarum showed the highest amount of total free amino acids (FAAs) by $45 \mathrm{~d}$ of incubation (Table 1). Glutamic acid and proline were the most abundant amino acids (ca. 28 and $32 \mathrm{mg} 100 \mathrm{~g}^{-1}$, respectively), followed by glutamine, $\gamma$-aminobutyric acid, phenylalanine and tryptophan. Proline was present in all model systems but not in experimental cheeses, possibly as a residue of $\beta$-casein degradation. Proline is usually the major FAA in the curd of several cheese varieties, such as León (Prieto et al., 2004), Armada (Fresno, Tornadijo, Carballo, Bernardo, \& González-Prieto, 1997) and BabiaLaciana (Franco, Prieto, Bernardo, González-Prieto, \& Carballo, 2003).

Accumulation of FAAs resulted in little conversion into volatile compounds (Table 2). Samples inoculated with $L b$. plantarum had the highest amounts of FAAs (Table 1) and the lowest amounts of VFAs (Table 2), whereas samples inoculated with E. faecium and all cultures combined showed the opposite trend. During ripening, samples inoculated with $E$. faecium showed low amounts of valine, phenylalanine, tryptophan and cysteine, the suggesting conversion of these FAAs into potential flavour compounds. The conversion of branched-chain, sulphur and aromatic amino acids by lactococci has been shown to be essential in cheese flavour development (Yvon, Thirouin, Rijnen, Fromentier, \& Gripon, 1997; Rijnen et al., 1999).

The contribution of plant rennet to the pool of VFAs appears to be very limited. Samples containing only the coagulant (Fig. 1) and samples containing only the microorganism (data not shown) did not lead to such high amounts of volatiles as found in those samples containing both; therefore, microbial action on hydrolyzed proteins appears to be responsible for production of most VFAs. In inoculated curdled samples, the increase in VFA content throughout maturation is clear (note the different scale on the y-axis of Figs. 2C and D). By $7 \mathrm{~d}$, acetic acid was the most abundant VFA (as a result of lactose metabolism), whereas iso-valeric acid was the major VFA in all samples 
Table 1

Content (mean \pm standard deviation) of free amino acids in curdled milk ( $\mathrm{mg} 100 \mathrm{~g}^{-1}$ curd), incubated for $45 \mathrm{~d}$ at $8-10^{\circ} \mathrm{C}$ and $95 \%$ relative humidity

\begin{tabular}{|c|c|c|c|c|c|c|}
\hline Amino acid & Milk $^{\mathrm{a}}$ & Milk $+L b$. plantarum & Milk + Leuc. mesenteroides & Milk + Lc. lactis & Milk + E. faecium & Milk + All \\
\hline Asp & $7.23 \pm 0.36$ & $6.54 \pm 1.16$ & $5.42 \pm 0.85$ & $0.00 \pm 0.00$ & $0.00 \pm 0.00$ & $0.00 \pm 0.00$ \\
\hline Glu & $15.30 \pm 1.45$ & $28.03 \pm 5.65$ & $14.02 \pm 1.51$ & $0.00 \pm 0.00$ & $0.00 \pm 0.00$ & $0.00 \pm 0.00$ \\
\hline Asn & $0.00 \pm 0.00$ & $0.00 \pm 0.00$ & $0.64 \pm 0.25$ & $0.00 \pm 0.00$ & $0.00 \pm 0.00$ & $0.00 \pm 0.00$ \\
\hline Ser & $0.00 \pm 0.00$ & $0.00 \pm 0.00$ & $0.00 \pm 0.00$ & $0.00 \pm 0.00$ & $0.00 \pm 0.00$ & $0.00 \pm 0.00$ \\
\hline Gln & $15.28 \pm 0.92$ & $15.60 \pm 4.33$ & $11.25 \pm 1.51$ & $0.00 \pm 0.00$ & $0.00 \pm 0.00$ & $0.00 \pm 0.00$ \\
\hline Gly & $2.45 \pm 0.47$ & $3.14 \pm 0.27$ & $2.55 \pm 0.59$ & $0.69 \pm 0.19$ & $0.46 \pm 0.13$ & $0.94 \pm 0.27$ \\
\hline His & $1.46 \pm 0.47$ & $0.00 \pm 0.00$ & $1.88 \pm 0.32$ & $1.51 \pm 0.40$ & $1.09 \pm 0.19$ & $0.89 \pm 0.26$ \\
\hline Tau & $0.39 \pm 0.19$ & $0.60 \pm 0.22$ & $0.43 \pm 0.14$ & $0.73 \pm 0.29$ & $0.50 \pm 0.03$ & $0.42 \pm 0.14$ \\
\hline GABA & $12.64 \pm 1.56$ & $8.75 \pm 2.03$ & $7.02 \pm 0.84$ & $5.70 \pm 0.80$ & $3.52 \pm 0.71$ & $3.63 \pm 0.94$ \\
\hline $\operatorname{Arg}+\mathrm{Thr}$ & $3.61 \pm 0.93$ & $3.80 \pm 1.05$ & $2.07 \pm 0.44$ & $0.00 \pm 0.00$ & $0.00 \pm 0.00$ & $0.00 \pm 0.00$ \\
\hline Ala & $4.24 \pm 1.39$ & $1.97 \pm 0.06$ & $0.36 \pm 0.15$ & $0.19 \pm 0.07$ & $0.00 \pm 0.00$ & $0.00 \pm 0.00$ \\
\hline Pro & $14.71 \pm 2.49$ & $32.05 \pm 5.04$ & $20.59 \pm 3.71$ & $9.46 \pm 1.33$ & $5.23 \pm 0.77$ & $0.41 \pm 0.04$ \\
\hline Tyr & $4.87 \pm 1.14$ & $4.44 \pm 0.27$ & $3.06 \pm 0.69$ & $6.54 \pm 1.08$ & $3.57 \pm 0.52$ & $1.10 \pm 0.29$ \\
\hline Val & $6.83 \pm 1.42$ & $3.54 \pm 0.36$ & $3.57 \pm 0.74$ & $2.56 \pm 0.93$ & $0.62 \pm 0.14$ & $0.74 \pm 0.23$ \\
\hline Met & $0.43 \pm 0.14$ & $0.54 \pm 0.16$ & $0.39 \pm 0.09$ & $0.00 \pm 0.00$ & $0.00 \pm 0.00$ & $0.00 \pm 0.00$ \\
\hline Cys & $3.53 \pm 0.82$ & $4.69 \pm 1.01$ & $4.42 \pm 0.78$ & $1.62 \pm 0.28$ & $1.60 \pm 0.31$ & $1.52 \pm 0.41$ \\
\hline Ile & $0.00 \pm 0.00$ & $0.64 \pm 0.16$ & $1.63 \pm 0.15$ & $0.00 \pm 0.00$ & $0.00 \pm 0.00$ & $0.00 \pm 0.00$ \\
\hline Leu & $5.96 \pm 0.39$ & $0.00 \pm 0.00$ & $0.46 \pm 0.17$ & $5.77 \pm 1.25$ & $2.57 \pm 0.12$ & $4.35 \pm 0.69$ \\
\hline Phe & $11.09 \pm 2.60$ & $5.26 \pm 0.56$ & $8.39 \pm 1.49$ & $0.96 \pm 0.18$ & $0.21 \pm 0.04$ & $0.64 \pm 0.18$ \\
\hline Trp & $3.63 \pm 2.23$ & $4.77 \pm 0.29$ & $2.01 \pm 0.51$ & $2.46 \pm 0.37$ & $1.93 \pm 0.25$ & $3.20 \pm 0.54$ \\
\hline Lys & $0.00 \pm 0.00$ & $0.00 \pm 0.00$ & $0.00 \pm 0.00$ & $0.00 \pm 0.00$ & $0.00 \pm 0.00$ & $0.00 \pm 0.00$ \\
\hline Total & 113.64 & 124.36 & 90.16 & 38.19 & 21.33 & 17.87 \\
\hline
\end{tabular}

"The column "milk" refers to the control sample, which consisted of curdled milk with no addition of microorganisms.

Table 2

Content (mean \pm standard deviation) of volatile fatty acids in curdled milk ( $\mathrm{mg} \mathrm{kg}^{-1}$ curd), incubated for $45 \mathrm{~d}$ at $8-10{ }^{\circ} \mathrm{C}$ and $95 \%$ relative humidity

\begin{tabular}{lcccrrr}
\hline Fatty acid & \multicolumn{1}{c}{ Milk $^{\mathrm{a}}$} & Milk + Lb. plantarum & Milk + Leuc. mesenteroides & Milk + Lc. lactis & Milk + E. faecium & Milk + All \\
\hline Acetic acid $\left(\mathrm{C}_{2}\right)$ & $9.77 \pm 6.94$ & $7.07 \pm 4.71$ & $4.86 \pm 3.00$ & $10.52 \pm 2.23$ & $6.92 \pm 0.14$ \\
Propionic acid $\left(\mathrm{C}_{3}\right)$ & $1.10 \pm 0.24$ & $5.23 \pm 2.56$ & $13.44 \pm 0.19$ & $5.99 \pm 1.41$ & $20.85 \pm 6.11$ \\
Iso-butyric acid $\left(\mathrm{iC}_{4}\right)$ & $0.44 \pm 0.07$ & $9.67 \pm 7.51$ & $17.22 \pm 12.43$ & $19.13 \pm 9.69$ & $39.25 \pm 7.33$ & $15.35 \pm 0.48$ \\
Butyric acid $\left(\mathrm{C}_{4}\right)$ & $26.96 \pm 7.31$ & $12.55 \pm 2.47$ & $21.91 \pm 7.79$ & $12.72 \pm 7.50$ & $39.08 \pm 3.56$ & $34.48 \pm 0.03$ \\
Iso-valeric acid $\left(\mathrm{iC}_{5}\right)$ & $0.64 \pm 0.31$ & $21.37 \pm 2.70$ & $113.73 \pm 2.78$ & $34.23 \pm 8.03$ & $135.81 \pm 15.57$ & $113.13 \pm 7.53$ \\
Caproic acid $\left(\mathrm{C}_{6}\right)$ & $26.31 \pm 2.59$ & $11.15 \pm 2.88$ & $13.15 \pm 5.31$ & $18.54 \pm 6.69$ & $43.49 \pm 19.16$ \\
Caprylic acid $\left(\mathrm{C}_{8}\right)$ & $43.48 \pm 6.23$ & $17.95 \pm 1.70$ & $21.96 \pm 12.98$ & $30.56 \pm 2.50$ & $49.97 \pm 18.67$ \\
Capric acid $\left(\mathrm{C}_{10}\right)$ & $54.42 \pm 6.60$ & $23.46 \pm 4.82$ & $36.57 \pm 22.23$ & $34.70 \pm 3.89$ & $52.78 \pm 12.99$ & $33.74 \pm 6.31$ \\
Lauric acid $\left(\mathrm{C}_{12}\right)$ & $4.56 \pm 0.16$ & $2.86 \pm 1.05$ & $4.32 \pm 2.70$ & $3.96 \pm 2.41$ & $5.08 \pm 1.13$ \\
Total & 167.7 & 108.44 & 242.85 & 162.39 & $38.12 \pm 13.42$ \\
\hline
\end{tabular}

aThe column "milk" refers to the control sample, which consisted of curdled milk with no addition of microorganisms.

after this time-ranging from 57.5 to $148.3 \mathrm{mg} \mathrm{kg}^{-1}$ curd. Iso-valeric acid arises from leucine catabolism brought about by an aminotransferase, and posterior oxidative decarboxylation of the corresponding keto-acid (Molimard \& Spinnler, 1996).

Iso-butyric and propionic acids appear as a consequence of microbial action (Table 2), and their concentration ranged from 5.2 to $39.3 \mathrm{mg} \mathrm{kg}^{-1}$ curd. The total amount of VFAs was highest in ET $\left(388.2 \mathrm{mg} \mathrm{kg}^{-1}\right.$ curd), followed by MX (309.6 $\mathrm{mg} \mathrm{kg}^{-1}$ curd) cheese-like systems - which is in agreement with the FAA profile (Table 1). High amounts of volatiles are not always viewed as an advantage, since they may have a negative impact upon the final product, due to extra bitterness and other off-flavours. Iso-valeric acid is responsible for the strong, rancid, piquant, cheesylike aroma that is typical of a ripened cheese, but which, when present in high amounts, can be unpleasant. In this study, the system with Lc. lactis produced moderate amounts of $\mathrm{iC}_{5}$ (ca. $34 \mathrm{mg} \mathrm{kg}^{-1}$ curd), but still produced an overall amount of volatiles close to those in the control sample. This was considered advantageous because this system exhibited the ripened aroma of Serra da Estrela cheese (which was not detected in the control system), but not as strong as in the other systems. The total amount of volatiles in this system was very close to that of the control, thus producing a balanced aroma.

\section{Experimental cheeses}

The FAA compositions of experimental cheeses were significantly different from each other, depending on the strain(s) used as starter and on the maturation time. The 

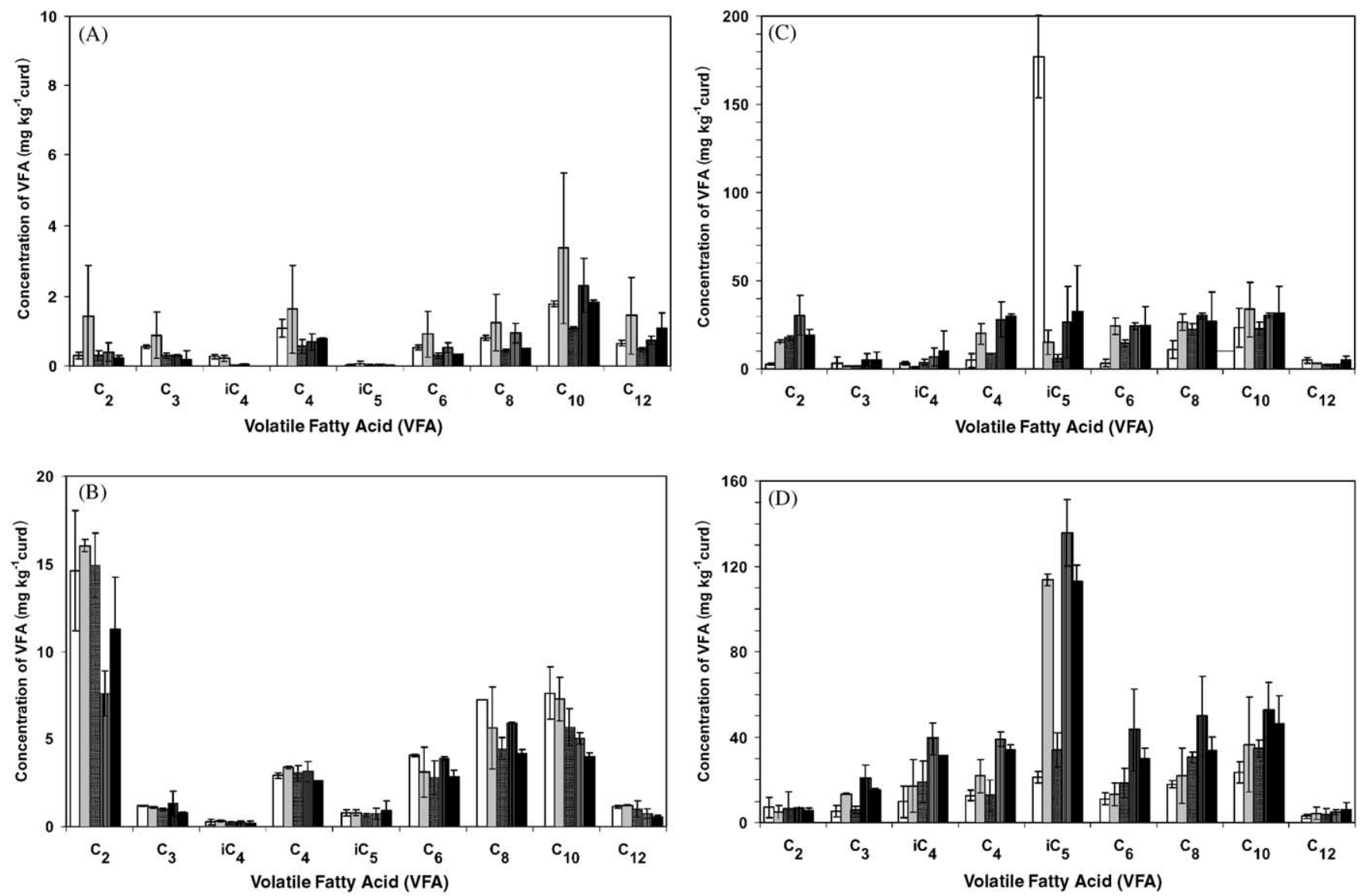

Fig. 2. Concentration (mean \pm standard deviation) of volatile fatty acids (VFAs) $\left(\mathrm{C}_{n}\right.$, where $n$ denotes number of carbon atoms), in cheese curd coagulated with Cynara cardunculus, and inoculated with Lactobacillus plantarum (- $\square-)$, Leuconostoc mesenteroides (- -), Lactococcus lactis (faecium (-而) and all four isolates $(1: 1: 1: 1)(-\mathbf{a}-)$, by 0 (A), 7 (B), 28 (C) and 45 (D) $\mathrm{d}$ of incubation, at $8-10^{\circ} \mathrm{C}$ and $95 \%$ relative humidity (iC 4 , iso-butyric acid; $\mathrm{iC}_{5}$, iso-valeric acid).

most abundant FAAs found in these cheeses (Fig. 3) were glutamic acid, valine, leucine, lysine, phenylalanine and tryptophan. Considering only the most abundant FAAs, pairwise comparisons unfolded differences among cheeses only for glutamic acid and tryptophan. MX cheeses differed significantly $(p<0.05)$, by $63 \mathrm{~d}$ of maturation, from all others in the content of glutamic acid (200-fold that of control cheeses, 2-fold that of LC cheeses and 22fold that of LB cheeses), and from CT and LC cheeses in the content of tryptophan (3.6-fold and 2.4-fold those of CT and LC cheeses, respectively). Glutamic acid results from transformation of $\alpha$-ketoglutarate, which is a product of transamination, a key reaction leading to formation of aroma compounds from amino acids (Yvon \& Rijnen, 2001). The conversion of aromatic amino acids (e.g. phenylalanine and tryptophan) can result in development of off-flavours, derived from such compounds as phenylethanol, $p$-cresol, indole, skatole, benzyl alcohol and benzoic acid, which can contribute to putrid, fecal or unclean flavours (van Kranenburg et al., 2002). Interestingly, dimethyl disulfide (DMDS) derived from methionine catabolism was also found in all cheese samples by $45 \mathrm{~d}$ of maturation, except in MX cheeses (this compound was not present in the cheese-like model systems).
Although the results pertaining to the model systems did not directly correlate to those found in cheese, model systems are a valuable intermediate between test tube experiments and cheese trials (Rehman, Fox, McSweeney, Madkor, \& Farkye, 2001). In fact, they provide controlled bacteriological conditions, that may be helpful in elucidating flavour generation pathways and are not as timeconsuming as pilot scale experiments.

The VFA profiles of cheeses manufactured with added strains of lactic acid bacteria are shown in Fig. 4. Cheeses manufactured with added cultures had higher concentrations of VFAs than control cheeses. The LB cheeses exhibited the highest amounts of $\mathrm{iC}_{4}, \mathrm{C}_{4}, \mathrm{iC}_{5}, \mathrm{C}_{10}$ and $\mathrm{C}_{12}$, and similar amounts of $\mathrm{C}_{2}, \mathrm{C}_{3}$ and $\mathrm{C}_{8}$ fatty acids as the $\mathrm{LC}$ cheeses. Cheeses manufactured with both isolates (MX) were not different from the control cheeses regarding the amounts of $\mathrm{C}_{2}, \mathrm{C}_{4}, \mathrm{iC}_{5}, \mathrm{C}_{6}$ and $\mathrm{C}_{8}$ fatty acids, whereas those manufactured with only one isolate were significantly different from the control cheeses. The highest contents of VFAs (ca. $272.1 \mathrm{mg} \mathrm{kg}^{-1}$ cheese) were found in LB cheeses by $63 \mathrm{~d}$, followed by LC $\left(202.1 \mathrm{mg} \mathrm{kg}^{-1}\right.$ cheese), MX (116.4 $\mathrm{mg} \mathrm{kg}^{-1}$ cheese) and CT $\left(43.2 \mathrm{mg} \mathrm{kg}^{-1}\right.$ cheese) cheeses, for the same ripening time. Butyric, iso-valeric and caproic acids were the most abundant VFAs in our 

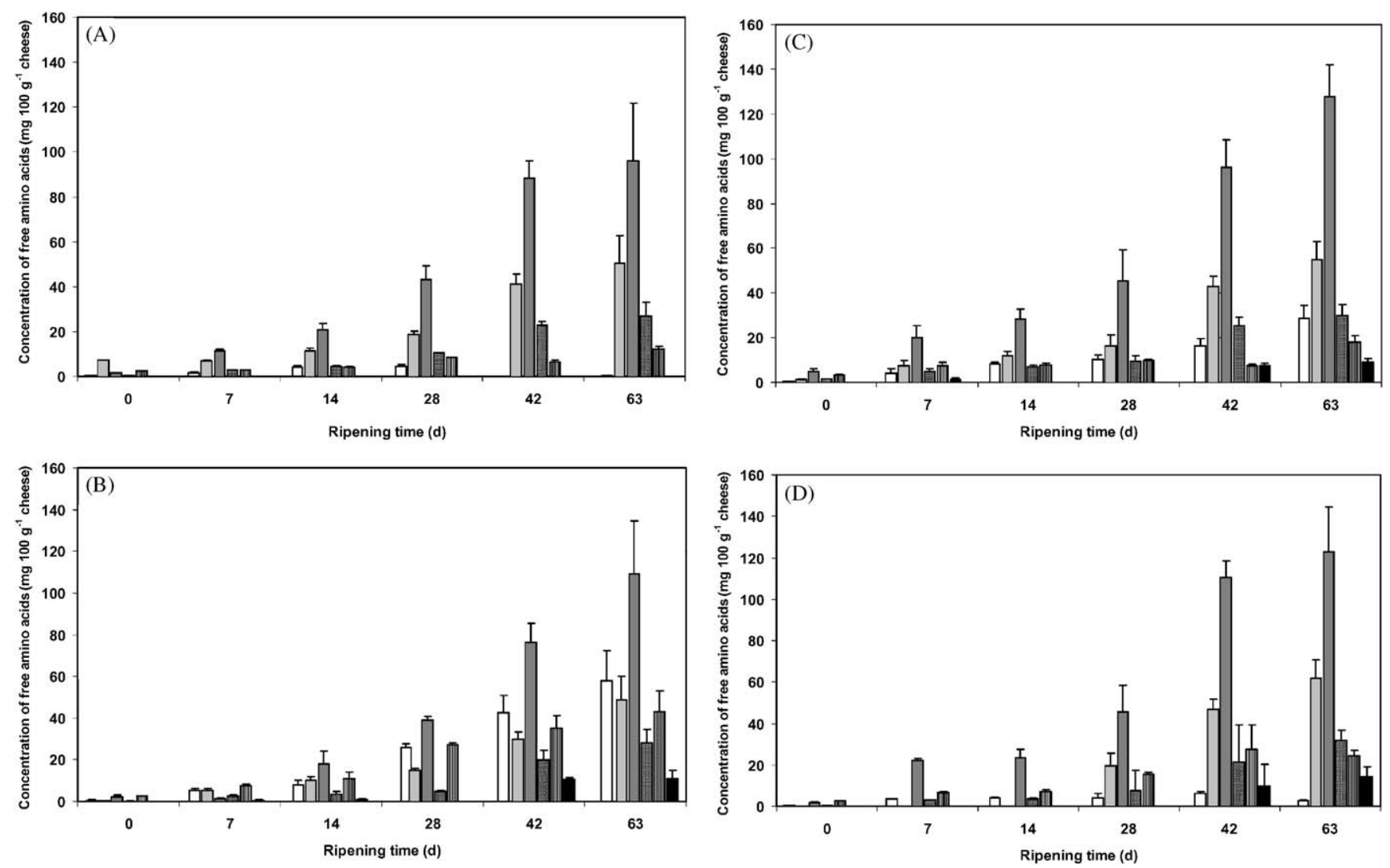

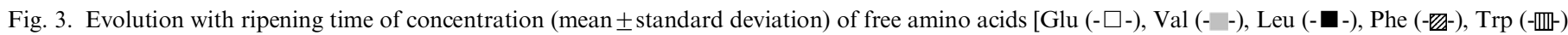
and Lys (-口-)], in cheeses manufactured without starter (A) and with addition of Lactobacillus plantarum (B), Lactococcus lactis (C) and Lactobacillus plantarum + Lactococcus lactis (1:1) (D).
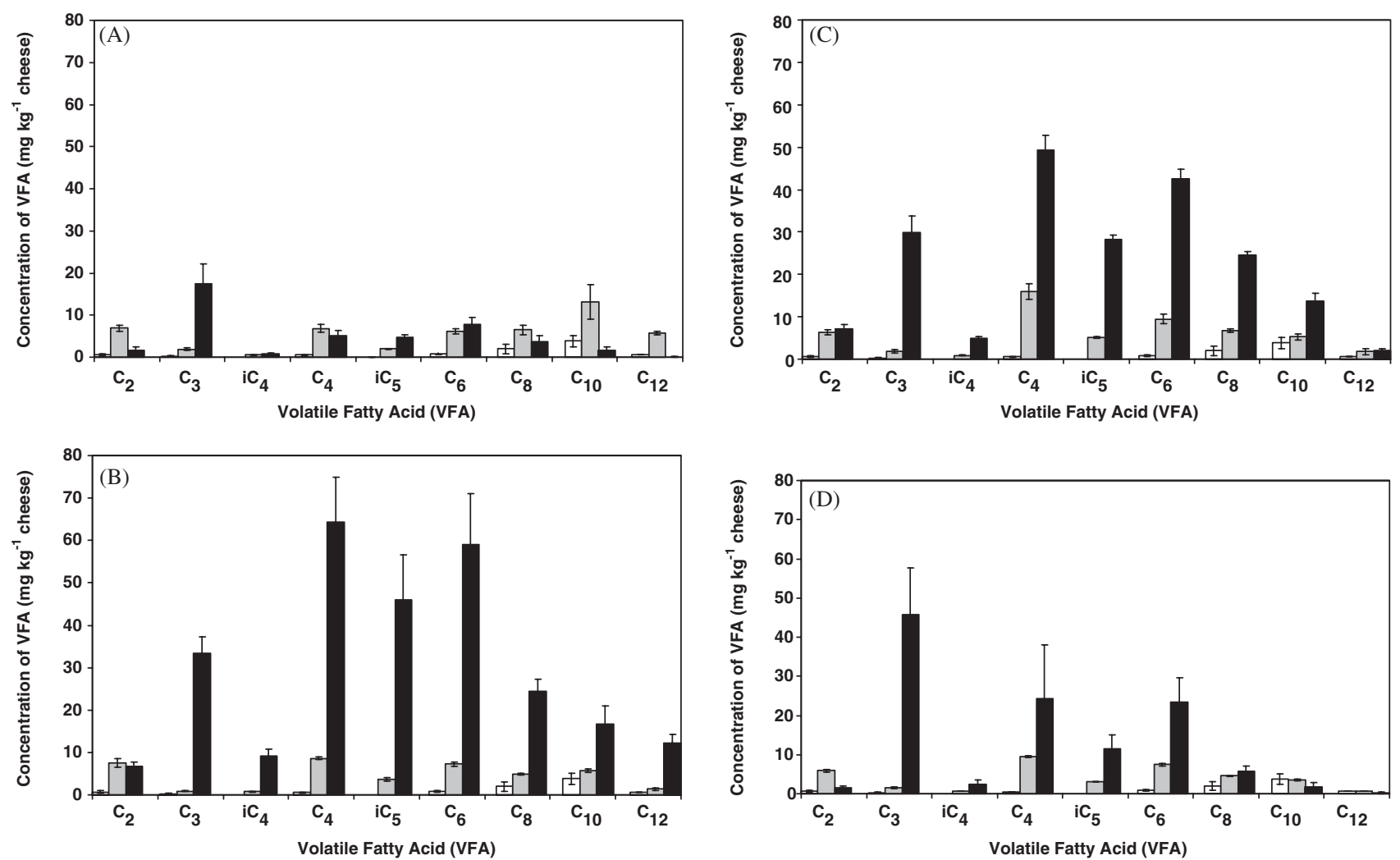

Fig. 4. Concentration (mean \pm standard deviation) of volatile fatty acids (VFAs) ( $C_{n}$, where $n$ denotes number of carbon atoms), in cheeses manufactured without starter (A) and with addition of Lactobacillus plantarum (B), Lactococcus lactis (C) and Lactobacillus plantarum + Lactococcus lactis (D) (1:1), by 0 (- $\square-), 28$ (--) and 63 (- - -) d of ripening ( $\mathrm{iC}_{4}$, iso-butyric acid; $\mathrm{iC}_{5}$, iso-valeric acid). 
cheese samples, hence suggesting that they are the major contributors to the overall aroma of this cheese. Butyric and caproic acids form mainly from lipolysis; the former accounts for an aroma very similar to that of iso-butyric acid, which arises from valine catabolism, and confers a cheesy, sweaty and sour odour (Dacremont \& Vickers, 1994). Iso-valeric acid, derived from leucine catabolism (Yvon \& Rijnen, 2001), has a rancid, cheesy, sweaty, putrid odour - that probably contributes to the longripened, harsh, piquant cheese aroma that is characteristic of this cheese (and of others manufactured from milk of small ruminants).

Sensory evaluation of similar cheeses (Macedo, Tavares, \& Malcata, 2004) rated LB and MX cheeses similar to control (CT) cheeses, whereas LC cheeses were found to be acidic and bitter. Lactobacillus sp., due to its high aminopeptidase activity, is known to reduce bitterness in cheese (Ardö, Larsson, Mansson, \& Hedenberg, 1989). Despite the larger amounts of volatiles found in LB cheeses, the panel rated these cheeses (Macedo et al., 2004) close to those manufactured without the addition of any starter culture. Inclusion of Lb. plantarum (alone or in a mixed culture) seemed advantageous, since such cheeses attained large levels of volatiles in a shorter time frame (Fig. 4B and D).

\section{Conclusions}

The cheese-like model system described allowed assessment of the contribution of various isolates to the production of aroma compounds from milk. However, when tested in cheese trials, the results were not similar. In the model system, Lb. plantarum exhibited low conversion ability of FAAs into volatiles. Iso-valeric acid (which is a product of leucine catabolism) was the most abundant VFA in all samples of model systems. In cheese, the most abundant VFAs were butyric, iso-valeric and caproic acids. Despite its low amino acid conversion ability in model systems, cheeses manufactured with the addition of $L b$. plantarum exhibited higher concentrations of volatiles (for the same ripening time) than those manufactured with $L c$. lactis or those without any starter addition - thus suggesting that addition of this culture may favour the overall aroma, and hence help accelerate ripening.

\section{Acknowledgements}

The authors gratefully acknowledge the Foundation for Science and Technology (FCT, Portugal) for partial funding under program PRAXIS XXI, through a Ph.D. fellowship (BD/9572/96) and project Deepening the knowledge on the role of enterococci, from manufacture through maturation of traditional cheeses (POCTI/AGR/36165/ 99) - with financial co-participation by Fundo Europeu de Desenvolvimento Regional (FEDER), and the European Commission for partial funding under program Fisheries and Agro-Industrial Research (FAIR), through project Control, acceleration and diversification of cheese flavour formed by enzymatic conversion of amino acids (FAIR-CT 97-3173).

\section{References}

Alonso, M. L., Alvarez, A. I., \& Zapico, J. (1994). Rapid analysis of free amino acids in infant foods. Journal of Liquid Chromatography, 17, 4019-4030.

Ardö, T., Larsson, P., Mansson, L., \& Hedenberg, A. (1989). Studies on peptidolysis during early maturation and its influence on low-fat cheese quality. Milchwissenschaft, 44, 485-490.

Ayad, E., Verheul, A., Wouters, J., \& Smit, G. (2000). Application of wild starter cultures for flavour development in pilot plant cheese making. International Dairy Journal, 10, 169-179.

Bosset, J. O., \& Gauch, R. (1993). Comparison of the volatile flavour compounds of six European "AOC" cheeses by using a new dynamic headspace GC-MS method. International Dairy Journal, 3, 359-377.

Buchin, S., Delague, V., Duboz, G., Berdagué, J. L., Beuvier, E., Pochet, S., et al. (1998). Influence of pasteurization and fat composition of milk on the volatile compounds and flavor characteristics of a semihard cheese. Journal of Dairy Science, 81, 3097-3108.

Centeno, J. A., Menéndez, S., Hermida, M., \& Rodríguez-Otero, J. L. (1999). Effects of addition of Enterococcus faecalis in Cebreiro cheese manufacture. International Journal of Food Microbiology, 48, 97-111.

Dacremont, C., \& Vickers, A. (1994). Concept matching technique for assessing importance of volatile compounds for Cheddar cheese aroma. Journal of Food Science, 59, 981-985.

Dirinck, P., \& de Winne, A. (1999). Flavour characterization and classification of cheeses by gas chromatographic-mass spectrometric profiling. Journal of Chromatography A, 847, 203-208.

Fox, P. F., \& Wallace, J. M. (1997). Formation of flavour compounds in cheese. Advances in Applied Microbiology, 45, 17-85.

Franco, I., Prieto, B., Bernardo, A., González-Prieto, J., \& Carballo, J. (2003). Biochemical changes throughout the ripening of a traditional Spanish goat cheese variety (Babia-Laciana). International Dairy Journal, 13, 221-230.

Fresno, J. M., Tornadijo, M. E., Carballo, J., Bernardo, A., \& GonzálezPrieto, J. (1997). Proteolytic and lipolytic changes during the ripening of a Spanish craft goat cheese (Armada variety). Journal of the Science of Food and Agriculture, 75, 148-154.

Frutos, M., Sanz, J., \& Martínez-Castro, I. (1991). Characterization of artisanal cheeses by GC and GC/MS analysis of their medium volatility (SDE) fraction. Journal of Agricultural and Food Chemistry, $39,524-530$.

Grappin, R., \& Beuvier, E. (1997). Possible implications of milk pasteurization on the manufacture and sensory quality of ripened cheese: A review. International Dairy Journal, 7, 751-761.

Kersters, K. (1985). Numerical methods in the classification of bacteria by protein electrophoresis. In M. Goodfellow, D. Jones, \& F. G. Priest (Eds.), Computer assisted numerical systematics (pp. 337-368). London, UK: Academic Press.

Lawlor, J. B., Delahunty, C. M., Wilkinson, M. G., \& Sheehan, J. (2002). Relationships between the gross, non-volatile and volatile compositions and the sensory attributes of eight hard-type cheeses. International Dairy Journal, 12, 493-509.

Macedo, A. C., Tavares, T. G., \& Malcata, F. X. (2004). Influence of native lactic acid bacteria on the microbiological, biochemical and sensory profiles of Serra da Estrela cheese. Food Microbiology, 21, 233-240.

Menéndez, S., Centeno, J. A., Godínez, R., \& Rodríguez-Otero, J. L. (2000). Effects of various Lactobacillus strains on the ripening and organoleptic characteristics of Arzua-Ulloa cheese. International Journal of Food Microbiology, 59, 37-46.

Menéndez, S., Godínez, R., Hermida, M., Centeno, J. A., \& RodríguezOtero, J. L. (2004). Characteristics of "Tetilla" pasteurized milk cheese 
manufactured with the addition of autochthonous cultures. Food Microbiology, 21, 97-104.

Molimard, P., \& Spinnler, H. E. (1996). Review: Compounds involved in the flavor of surface mold-ripened cheeses: Origins and properties. Journal of Dairy Science, 79, 169-184.

Prieto, B., Franco, I., Fresno, J. M., González-Prieto, J., Bernardo, A., \& Carballo, J. (2004). Effect of ripening time and type of rennet (farmhouse rennet from kid or commercial calf) on proteolysis during the ripening of Léon cow milk cheese. Food Chemistry, 85, 389-398.

Rehman, S. U., Fox, P., McSweeney, P. L. H., Madkor, S. A., \& Farkye, N. Y. (2001). Alternatives to pilot plant experiments in cheeseripening studies. International Journal of Dairy Technology, 54, $121-126$.

Reis, P. M., Lourenço, P. L., Domingos, A., Clemente, A. F., Pais, M. S., \& Malcata, F. X. (2000). Applicability of extracts from Centaurea calcitrapa in ripening of bovine cheese. International Dairy Journal, 10, 775-780.

Rijnen, L., Delacroix-Buchet, A., Démaizières, D., le Quéré, J. L., Gripon, J. C., \& Yvon, M. (1999). Inactivation of lactococcal aromatic aminotransferase prevents the formation of the floral aroma com- pounds from aromatic amino acids in semi-hard cheese. International Dairy Journal, 9, 877-885.

Sousa, M. J., \& Malcata, F. X. (2002). Advances in the role of a plant coagulant (Cynara cardunculus) in vitro and during ripening of cheeses from several milk species. Le, Lait, 82, 151-170.

Tavaria, F. K., Silva-Ferreira, A. C., \& Malcata, F. X. (2004). Volatile free fatty acids as quality indicators for consumption of Serra da Estrela cheese. Journal of Dairy Science, 87, 4064-4072.

Vandeweghe, P., \& Reineccius, G. A. (1990). Comparison of flavor isolation techniques applied to Cheddar cheese. Journal of Agricultural and Food Chemistry, 38, 1549-1552.

van Kranenburg, R., Kleerebezem, M., Vlieg, J., Ursing, B., Boekhorst, J., Smit, B., et al. (2002). Flavour formation from amino acids by lactic acid bacteria: Predictions from genome sequence analysis. International Dairy Journal, 12, 111-121.

Yvon, M., \& Rijnen, L. (2001). Cheese flavour formation by amino acid catabolism. International Dairy Journal, 11, 185-201.

Yvon, M., Thirouin, S., Rijnen, L., Fromentier, D., \& Gripon, J. C. (1997). An aminotransferase from Lactococcus lactis initiates conversion of amino acids to cheese flavor compounds. Applied and Environmental Microbiology, 63, 414-419. 